\title{
GINCANAS COMO ESPAÇO DE FORMAÇÃO DOCENTE: das (inter)faces possíveis em um curso de Pedagogia
}

\section{Gymkhanas as a space for teacher training: of the possible (inter) faces in a course of Pedagogy}

Douglas Pereira da Costa ${ }^{1}$

\begin{abstract}
RESUMO: As interfaces constitutivas dos percursos formativos de professores são vastas, bem como, suas possibilidades nas mais variadas facetas do conhecimento científico e humano. Diante dessa variedade de experiências possíveis, neste estudo, tratou-se sobre a gincana acadêmica, caracterizada como uma atividade de grande impacto experiencial para graduandos de ensino superior. O estudo trata-se de um relato de experiência docente sobre a prática educativa ao lecionar a disciplina de Gestão e Educação Ambiental a alunos de uma turma de Pedagogia. $\mathrm{Na}$ ocasião foi planejada e executada uma gincana com título e tema: "Somos todos um só, pelo Brasil, pelo meio ambiente", com o objetivo de refletir de forma lúdica, divertida e por meio de expressões diversas, sobre a temática de Educação Ambiental (EA) na formação dos professores. Das experiências extraiu-se os saberes experiências, pelo conjunto de tarefas realizadas, capazes de gerar múltiplos sentidos para a formação acadêmica, profissional, social, cultural e cidadã dos graduandos, de forma ativa, participativa, lúdica e responsável. Assim, foi trilhado um caminho divertido e rico em interações, experiências e expressões humanas e formativas que propiciaram o alcance do objetivo proposto com a gincana, firmando-a como um recurso metodológico de grande valia no processo de formação de professores, sendo um espaço adaptável à todas as áreas, públicos e níveis de ensino formalizado.
\end{abstract}

Palavras-chave: Formação de professores. Gincana. Pedagogia. Relato de experiência.

ABSTRACT: The constitutive interfaces of the formative paths of teachers are vast, as well as their possibilities in the most varied facets of scientific and human knowledge. Faced with this variety of possible experiences, this study was about the academic gymnastics, characterized as an activity of great experiential impact for undergraduates of higher education. The study is an account of teaching experience on the educational practice when teaching the discipline of Management and Environmental Education to students of a group of Pedagogy. At the time, a gymkhana was planned and executed with a title and theme: "We are all one, for

\footnotetext{
${ }^{1}$ Mestre em Educação. Especialista em Psicopedagogia e Educação Especial e Licenciado em Pedagogia. Professor Bolsista do CETEC (Teresina-PI). E-mail: douglascosta.15@hotmail.com
}

Cadernos Cajuína, V. 4, N. 1, 2019, p. 84 - 104.

ISSN: 2448-0916 
Brazil, for the environment", with the objective of reflecting in a fun, fun and through diverse expressions on the theme of Environmental Education (EA) in teacher training. From the experiences, the experiences were extracted by the set of tasks carried out, capable of generating multiple meanings for the academic, professional, social, cultural and citizen education of the undergraduates, in an active, participatory, playful and responsible way. Thus, a fun and rich path was developed in human and formative interactions, experiences and expressions that propitiated the achievement of the goal proposed with the gymkhana, establishing it as a methodological resource of great value in the process of teacher training, being an adaptive space to all areas, public and levels of formal education.

Keywords: Teacher training. Gymkhana. Pedagogy. Experience report.

\section{CONSIDERAÇÕES INICIAIS}

As interfaces constitutivas dos percursos formativos de professores são vastas, bem como, suas possibilidades nas mais variadas facetas do conhecimento científico e humano. $\mathrm{Na}$ atualidade, os problemas sociais de variadas ordens, insurgem como objetos de estudos acadêmicos, pois é no campo universitário que emergem saberes científicos impulsionadores de políticas e transformações sociais, além do mais, é o local onde são formados docentes para atuação, principalmente, na educação básica. Dentre esses problemas, destaca-se as questões relativas às ações destrutivas do homem sobre o meio ambiente, as quais, têm se intensificado com o passar do tempo. Assim, este estudo apresenta reflexões e vivências socioambientais em Instituições de Ensino Superior (IES), com foco na Educação Ambiental (EA).

A EA, segundo a Lei de № 9.795, de 27 de abril de 1999, que institui a Política Nacional de Educação Ambiental (PNEA), deve estar presente em todos os níveis e modalidades do ensino formal ofertado em território nacional. Diante disso, os cursos de formações de professores são direcionados a incluírem nos percursos formativos dos graduandos, em todas as disciplinas, discussões fomentadoras da constituição crítica e social numa perspectiva socioambiental (BRASIL, 1999).

Pequeno; Guimarães; Almeida (2009) afirmam que as universidades não podem fugir dessa realidade. E assim, para que a EA seja uma verdade prática, se faz necessário que as instituições de nível superior, em parcerias com docentes, assumam a responsabilidade de diversificarem e adicionarem conteúdos e 
metodologias para fins específicos de uma EA, num dimensão ampla e crítica. Nesse contexto, gincanas culturais tornam-se potentes recursos didáticos em inter (faces) ativas, interdisciplinares e experienciais possíveis de implementação dessa vertente educativa no trabalho docente.

Este estudo objetiva apresentar, de maneira contextualizada, um relato de experiência docente sobre a realização de uma gincana acadêmica a partir do tema EA, envolvendo alunos de uma turma de Licenciatura em Pedagogia de uma faculdade privada, em regime semipresencial, na cidade de Aroazes, Piauí.

Essa discussão se assenta sobre a relevante necessidade de contribuir com discussões acerca de métodos e técnicas educacionais na área da temática abordada, em todo e qualquer nível de ensino, mais especificamente, no nível superior, durante os percursos de formação de professores para atuar na educação básica.

\section{2. (INTER)FACES TEÓRICAS: GINCANA E EDUCAÇÃO AMBIENTAL NO ENSINO SUPERIOR}

Atualmente, é perceptível a forma como a educação e seus moldes enrijecidos têm sofrido alterações significativas. Nesse ambiente de transformações, os métodos e práticas educativas tradicionais vão sendo, aos poucos, substituídos por metodologias ativas no processo de ensino e aprendizagem. Morán (2015) relata as mudanças envolvidas no ensino disciplinar, por meio de propostas de projetos interdisciplinares. Pelas palavras do autor, percebe-se o quanto o aluno passa a ser protagonista nas suas trajetórias formativas e na apropriação do conhecimento.

Diante desse cenário, surgem aspectos inovadores nas IES, como marcos característicos dos avanços sociais em seus diversos segmentos. Sendo assim, Morin (2007, p. 17) garante que o processo de adaptação entre IES e sociedade é complementar, visto que "não se trata apenas de modernizar a cultura, mas de culturalizar a modernidade". Dessa forma, pensar educação no nível superior nos conduz para contextos dialógicos, nos quais a produção de conhecimento transcende o trivial das leituras e exposições em salas de aulas, rompendo com barreiras impostas pela mecanização do ensino tradicional. 
Para que tal quebra de parâmetros preestabelecidos aconteça, além dos diálogos e reflexões, se faz necessário o desenvolvimento do fazer pedagógico inovador. Porém, para muitos, inovação é sinônimo apenas da inserção tecnológica nos procedimentos de ensino e da aprendizagem. No entanto, a inovação ativa preocupa-se em colocar o aluno no centro de momentos e ambientes que viabilizem o autodesenvolvimento, através de ações do aprender e da geração de saberes.

Diante disso, no contexto dessa pesquisa, somos arremetidos ao conceito de gincana, como o "conjunto de provas disputadas entre grupos, em que os concorrentes devem seguir um percurso complicado e entremeado de obstáculos que resultam em incidentes cômicos [...] Competição em que os participantes (individual ou equipe) precisam responder perguntas ou cumprir tarefas" (DICIO, online, 2018), e assim, estabelecer relações diretas com as metodologias ativas, que são "[...] baseadas em atividades, desafios, problemas, jogos e onde cada aluno aprende no seu próprio ritmo e necessidade e também aprende com os outros em grupos e projetos" (MORÁN, 2015, p. 17).

A gincana, enquadrando-se como uma metodologia ativa, desmistifica a primeira impressão que temos a seu respeito, por não ser uma prática de origem recente e tecnológica em conjunturas escolares. No entanto, oportuniza ao alunado de nível superior experiências de autogerenciamento, individualmente e em conjunto, do processo de formação pautado nos desafios propostos, nos jogos vivenciados e na resolução de problemas teórico-práticos do mundo atual.

Em muitos casos, são estabelecidas visões sobre o ensino superior como um ambiente não permissível de brincadeiras, jogos e ludicidade, devido se tratar de um universo de produções acadêmicas científicas e de preparo para o mercado de trabalho. Mas, Nóvoa (1997), acerca da formação de professores, ressalta que o professor é antes de tudo, uma pessoa e que tal pessoa, constitui-se em professor, e mais ainda, que o adulto tem como referência de saber aquilo que está ligado às suas experiências. Nesse caso, a gincana proporciona experiências, em variadas expressões de linguagens e em interações interpessoais, contribuindo para as interfaces constitutivas do ser professor.

Larrosa (2002) é profundamente defensor da experiência como potência formadora e transformadora daqueles que a vivenciam. No entanto, o autor apresenta fatores que impossibilitam as existências experimentais nos aparatos educacionais contemporâneos, permeados pela sociedade informacional. E 
enumera esses fatores na seguinte ordem: informação, opinião, a falta de tempo e excesso de trabalho. Nos sentidos das suas palavras, entendemos que as muitas e aligeiradas informações sobre determinados assuntos não representam uma aprendizagem ou a formação de professores, assim como as opiniões fundamentadas em tais informações também não.

O autor levanta a premissa de que investimos mais tempo na atividade acadêmica e burocrática das IES e temos, cada vez menos tempo para viver aquilo que possa nos passar como experiência na trajetória formativa, preocupados em obter mais informações fluidas e aceleradas. Tal fato, pode ser considerado fruto do excesso de trabalho que provoca o distanciamento com as realidades experimentais. Pois, é "[...] experiência aquilo que 'nos passa', ou que nos toca, ou que nos acontece, e ao nos passar nos forma e nos transforma. Somente o sujeito da experiência está, portanto, aberto à sua própria transformação" (LARROSA, 2002, p. 25-26). Ou seja, a experiência é o que acontece com e no ser humano, sendo capaz de mudá-lo; é aquilo que não somente passa como informação reproduzida, mas o experimento que o atravessa, formando-o como sujeito.

Para Sampaio; Barros (2015), gincanas proporcionam aos envolvidos (discentes e docentes), novas experiências consideradas essenciais no aprimoramento de suas formações. Percebe-se então, que gincanas são campos experimentais riquíssimos e aliadas fortíssimas contra os inimigos dos saberes experienciais, capazes de fazer com que sujeitos sejam tocados, vivenciem acontecimentos, façam acontecer e que sejam atravessados pela dimensão socioambiental, necessária para a sua formação e ampla transformação.

Nesse sentido, no que tange a garantia de capacitação docente para um ensino nos termos da EA, essa está atrelada à inclusão da dimensão ambiental na formação e atualização dos educadores de todos os níveis e modalidades de ensino (BRASIL, 1999). A partir dessa concepção legal, entende-se o devido lugar de integração do meio ambiente, numa perspectiva crítico-reflexiva, aos discentes de nível superior.

A EA é um campo inovador do saber, que, ao longo do tempo, tem conquistado seu espaço legal e dentro do território educacional, por meio de um processo histórico marcado por lutas e progressões. São os marcos legais garantidos, a exemplo da Lei 9795/99, que fazem das IES partes integrantes e indispensáveis na construção do saber ambiental, na elaboração de políticas, 
disseminação de pesquisas e na formação de profissionais da educação em um cenário marcado pelos desafios das racionalidades técnicas, práticas e críticas que partem de uma perspectiva paradoxal espelhada pela tensão entre o contexto global e a realidade local (PEQUENO; GUIMARÃES; ALMEIDA, 2009).

A PNEA, no Art. 1ำ, por meio da Lei 9.795/99, conceitua EA:

Art. 1ํ Entendem-se por educação ambiental os processos por meio dos quais o indivíduo e a coletividade constroem valores sociais, conhecimentos, habilidades, atitudes e competências voltadas para a conservação do meio ambiente, bem de uso comum do povo, essencial à sadia qualidade de vida e sua sustentabilidade (BRASIL, 1999).

Fundamentados no exposto acima, mais uma vez, podemos vislumbrar as interfaces teóricas estabelecidas neste estudo. Ao entender que a EA é desenvolvida por meio de processos, os associamos ao desenvolvimento das gincanas em face às tematizações de meio ambiente e às variedades de assuntos pertinentes. Assim, destaca-se a gincana, em termos socioambientais, como uma prática pedagógica coletiva que fornece, aos graduandos, meios de pensamentos autônomos na constituinte formativa profissional e pessoal, por meio da construção de valores, conhecimentos, habilidades, atitudes e competências.

$\mathrm{Na}$ gincana de nível acadêmico, ainda há a interligação estendida dos aspectos formativos individuais aos coletivos e vice-versa, anteriormente mencionados pela EA, ao que Nóvoa (1997) chama de autoformação participada, que também, relaciona-se aos princípios das metodologias ativas, que são, por natureza, participativas e em coletividade, mas que contribuem para uma formação individual, particular e identitária. Toda essa contextualização coincide com o relato do autor, que afirma: "a formação deve estimular uma perspectiva critico-reflexiva, que forneça aos professores os meios de um pensamento autónomo e que facilite as dinâmicas de autoformação participada" (NÓVOA, 1997, p. 25).

A articulação da EA ao ensino superior, pode dar-se por meio da formação inicial e continuada, da pesquisa, da extensão universitária, de projetos e outras ações, tendo em vista que, as instituições educativas possuem a incumbência de promover a EA agregada aos programas educacionais ofertados, contando com atividades concretizadas pelo desenvolvimento de estudos, pesquisas e experimentações (BRASIL, 1999). 
A gincana cultural de meio ambiente é um espaço de experimentações e pesquisas correlacionadas ao saber ambiental, que são saberes constituídos pela racionalidade ambiental em níveis distintos de produção, proliferação e execução prática dos mecanismos políticos desse cunho, nos produtos das atividades de estudos e nas ações educativas. "O saber ambiental emerge do espaço de exclusão gerado no desenvolvimento das ciências, centradas em seus objetos de conhecimento, e que produz o desconhecimento de processos complexos que escapam à explicação dessas disciplinas" (LEFF, 2002, p. 145).

A tentativa de integrar o saber ambiental ao processo disciplinar no desenvolvimento das ciências, ganha enfoque principal na inter, multi e tansdisciplinaridade que implicam em possibilidade epistemológicas e pedagógicas contribuintes para o desenvolvimento do processo didático-metodológico do trabalho docente em sala de aula. Para Fernandez (2005, p. 1), a "[...] interdisciplinaridade refere-se a concepção de ensino e de currículo, baseada na interdependência entre os diversos ramos do conhecimento". O caráter interdisciplinar em EA é objeto das ações de estudos, pesquisas e experimentações enunciados dentro da PNEA.

$\S 30$ As ações de estudos, pesquisas e experimentações voltar-se-ão para:

I - o desenvolvimento de instrumentos e metodologias, visando à incorporação da dimensão ambiental, de forma interdisciplinar, nos diferentes níveis e modalidades de ensino;

II - a difusão de conhecimentos, tecnologias e informações sobre a questão ambiental;

III - o desenvolvimento de instrumentos e metodologias, visando à participação dos interessados na formulação e execução de pesquisas relacionadas à problemática ambiental;

IV - a busca de alternativas curriculares e metodológicas de capacitação na área ambiental;

$\mathrm{V}$ - o apoio a iniciativas e experiências locais e regionais, incluindo a produção de material educativo (BRASIL, 1999).

Em consonância com os incisos ilustrados acima, as ações de experimentações devem ser posicionadas de modo a colaborar com o desenvolvimento de metodologias e instrumentos participativos e correlatos à problemática ambiental, bem como, uma prática pedagógica que vise a alternância de estratégias curriculares e metodológicas para a formação socioambiental de educadores enquadrados nos diferentes níveis e modalidade de ensino. 
A contextualização de gincana traça novas interfaces com os dois pontos anteriormente citados acerca da EA, que, em conjunto, são: linguagens e interações constitutivas de professores em formação. Primeiramente, no que trata sobre o fundamento da busca por alternativas metodológicas, assim, a ação docente na elaboração e execução de gincanas, como metodologia de ensino, diversifica a práxis educativa. E, por outro lado, a capilaridade sugestiva de tarefas, jogos e atividades possíveis de aplicações junto aos discentes no decorrer de uma gincana, concretiza a interdisciplinaridade eficazmente, com base na interdependência dos variados ramos do conhecimento, no caso em estudo, dos saberes experienciais ambientais.

Portanto, as breves interconexões dos conceitos, marcos legais e teóricos retratados apontam para interfaces significativas no desenvolvimento do sujeito, que é constituído em professor numa nuance de posicionamentos necessários ao cenário socioambiental, em adaptações conjuntas no processo formativo de docentes dentro dos campos universitários, ilustrando as possibilidades formativas participativas de professores por meio de gincanas ao viés da emergência da EA.

\section{METOdOLOGIA: DAS EXPERIÊNCIAS POSSÍVEIS NO CURSO DE PEDAGOGIA}

O estudo trata-se do relato de uma experiência profissional docente, vivenciada ao lecionar a disciplina de Gestão e Educação Ambiental a aluno de uma turma de Licenciatura em Pedagogia de uma faculdade privada, na modalidade semipresencial, na cidade de Aroazes, estado do Piauí, durante o primeiro semestre de 2018. Tomamos por base os pensamentos de Larrosa (2002, p. 26), sobre a experiência e seus saberes, quando nos diz: "o saber de experiência se dá na relação entre o conhecimento e a vida humana". Assim, evidenciamos um cunho qualitativo na pesquisa, ao deslumbrar a formação social, humana e, consequentemente, profissional dos indivíduos em estudo (MINAYO, 2001).

Acredita-se que os apontamentos teóricos apresentados sejam verídicos e cabíveis para a contextualização no desenvolvimento metodológico ativo de aulas com alunos de nível superior. Pautado nisso e no que afirma a Lei 9.795, acerca da "[...] busca de alternativas curriculares e metodológicas de capacitação na área 
ambiental" (BRASIL, 1999), foi planejada e executada a gincana com título e tema "Somos todos um só, pelo Brasil, pelo meio ambiente".

O objetivo da gincana define o seu significado. Nesse caso, visou refletir, de forma lúdica, divertida e por meio de experiências teórico-práticas, sobre a EA na formação dos graduandos em Pedagogia, bem como, sobre assuntos pertinentes à relação do homem com o meio natural em variados aspectos, enfatizando ações de conservação e restauração do meio ambiente no desenvolvimento de saberes experienciais, conhecimentos, valores, habilidades, competências e atitudes.

O trabalho lúdico e experiencial com a gincana desenvolve diversas habilidades e temas/assuntos dentro das disciplinas, o trabalho em equipe, dentre outras vantagens apontadas por Sampaio; Barros (2015). Porém, considera-se relevante relatar que a experiência vivenciada por docente e alunos é diferente do experimento científico, ou seja, os acontecimentos comuns aos envolvidos geram experiências e saberes subjetivos, particulares e, ao mesmo tempo, plurais, diferentemente dos experimentos categóricos e homogêneos aos seus participantes (LARROSA, 2002). Sendo assim, relatamos os acontecimentos da gincana, na singularidade experiencial do professor universitário em diálogo com abordagens teórico-filosóficas.

Antes da narração e descrição dos acontecimentos da gincana, é essencial compreender o ponto de partida que impulsionou a materialização dessa prática educativa. Para Larrosa (2002), o sujeito da experiência é um apaixonado nos mais variados significados da palavra paixão. Na empreitada de professor de nível superior, o docente que opta por não permitir-se ser tocado pelas experiências, enrijece-se sem sentimentos de padecimentos e responsabilização em relação ao seu alunado, fazendo com que a paixão, como "experiência do amor" pela docência, seja usurpada.

Dessa forma, o professor-experimentador-apaixonado é possuído pelo desejo de propiciar uma formação em metodologias ativas e participativas, o que faz suas metodologias arderem por diversidades de práticas metodológicas, capazes de atender aos objetivos das disciplinas na constituição dos alunos em professores. Assim, das experiências possíveis, a gincana foi caracterizada como de grande impacto experiencial para os estudantes da turma de Pedagogia, tendo em vista que nunca haviam participado de atividade semelhante, bem como, de teor semelhante ao que foi proposto, a partir da ementa da disciplina Gestão e Educação Ambiental. 
A proposta foi apresentada a uma turma de 17 graduandos de diversas idades, compreendidas entre 24 e 60 anos. Do total, 7 são educadores atuantes na rede municipal de ensino, dois quais, 5 residem e são professores em comunidades da zona rural de Aroazes, cidade localizada a $225 \mathrm{~km}$ da capital do estado, Teresina. Os estudantes, em comum acordo, consideraram a ideia pertinente e, prontamente, prontificaram-se em viver tal experiência, juntamente com o professor.

Por meio de sorteio, a turma foi dividida em duas equipes, cada uma com um líder, também, escolhido por sorteio. Após as equipes formadas, professor e líderes se reuniram para a apresentação dos objetivos, disposições gerais sobre o regulamento $e$ as provas que seriam de conhecimento antecipado das equipes. $\mathrm{E}$ assim, foram acertados detalhes, como as cores que representariam as duas equipes, decididas por verde e amarela, pois estávamos em ano e período de Copa do Mundo de futebol, conjunto de fatos conexos ao tema da gincana; e, ainda, foi combinada a data de realização, um dia de aula com encontro presencial. Ressaltase que a turma funciona em regime semipresencial, sendo assim, também ficou acordado que seria durante os dois turnos (matutino e vespertino) do referido dia.

Um outro ponto importante discutido foi o local em que aconteceria a culminância das atividades. Então, foi escolhido o fundo de um quintal, com acesso a roça, bem arborizado por mangueiras e coqueiros e com uma piscina, um local propício a proporcionar o contato com o meio ambiente natural. A partir de então, tornou-se responsabilidade dos líderes, a mobilização de suas equipes para o trabalho em conjunto, a articulação para o cumprimento das provas e motivação de todos participantes, de maneira que a unanimidade fosse participativa, proativa e criativa.

\section{RESULTADOS E DISCUSSÃO DAS (INTER)FACES EXPERIENCIAIS}

De início, destaca-se a importância do planejamento, para elaboração e execução da gincana, algo que requer dedicação e empenho por parte do docente, mas que no decorrer do trajeto educativo se torna prazeroso e gratificante. Nesse caso, a experiência docente trouxe inúmeros aspectos que ratificam isso, em sentidos subjetivos, científicos, sociais e educacionais. A iniciativa é fruto da superação da falta de tempo e excesso de trabalho comum aos professores universitários e que confrontam os saberes da experiência (LARROSA, 2002). Para 
Nóvoa (1997, p. 29), "[...] falar de formação de professores é falar de um investimento educativo dos projectos da escola". Nessa linha de pensamento, entendemos o quanto mudanças de práticas pedagógicas são investimentos no magistério, capazes de tirar professores da zona de conforto. No entanto, para que essa inovação aconteça é necessário passar pela experiência da mudança de nível organizacional escolar, curricular e metodológico.

Retomando a escolha do lugar para os acontecimentos da gincana, percebeu-se que, pelo contato com o meio natural em uma realidade local, houve a produção de dois sentidos discursivos sobre esse aspecto, a vertente socioambiental e a construção de valores pelo educando, a partir de sua realidade, ambos caracterizados por Fernandez (2005), obedecendo ao princípio da EA pela abordagem articulada das questões ambientais locais, regionais, nacionais e globais (BRASIL, 1999).

Por tratar-se de discentes de ensino superior, já atuantes ou futuros professores da educação básica, a gincana também se vinculou como um exemplo metodológico teórico-prático, possível de adaptação para suas realidades como professores, fazendo da EA contínua e permanente, conforme a recomendação da PNEA (BRASIL, 1999), ou ainda, para sua real "[...] efetivação nos processos formais de ensino, especialmente da educação básica, impõe a necessidade da formação de educadores/as. Uma atribuição que está posta para as instituições de ensino superior" (PEQUENO; GUIMARÃES; ALMEIDA, 2009, p. 02).

Para o início da experiência, considerada como um dia de aula letivo, as equipes foram enfileiradas com a Bandeira do Brasil ao centro, para a execução do Hino Nacional, dando ênfase a importância do patriotismo pelos símbolos nacionais e como paixão para preservação da natureza, que faz do pais, naturalmente, um gigante. Tudo isso, aproveitando o clima de Copa do Mundo de Futebol, em que brasileiros torcem em unidade e em concordância com o tema "Somos todos um só, pelo Brasil, pelo meio ambiente". 
Imagens 01 e 02: Entrada dos alunos e execução do Hino Nacional
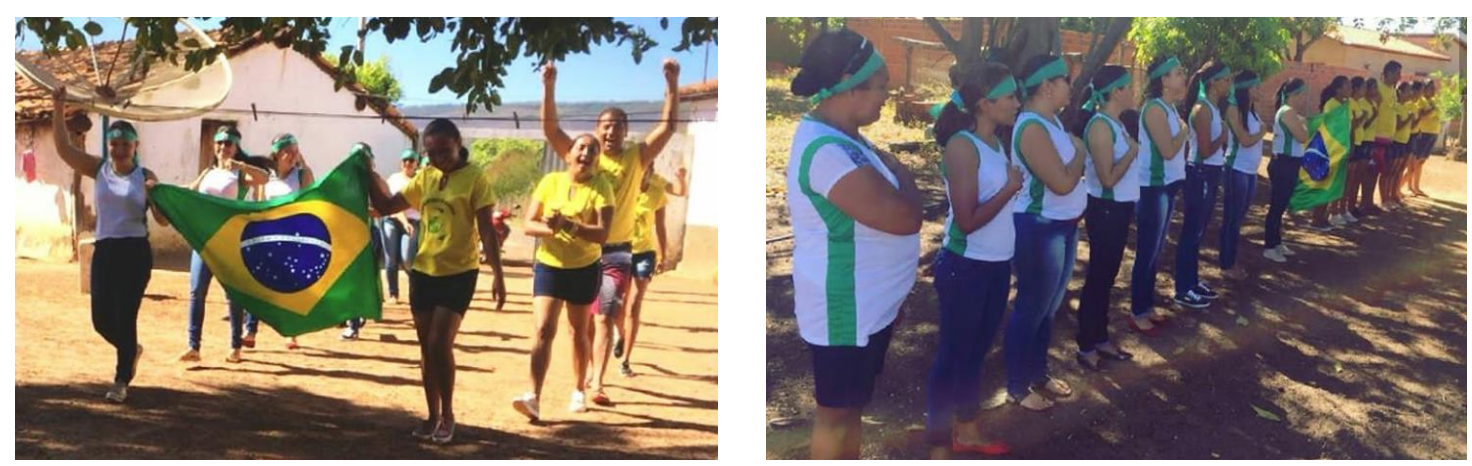

Fonte: Arquivo pessoal do professor/pesquisador (2018)

Posteriormente, foram firmados acordos, com base em regras de convivência, respeito e ética, para melhor relacionamento entre as equipes durante as atividades. Primeiramente, foram executadas as de conhecimento prévio, iniciando pelos nomes atribuídos, bem como, suas apresentações em bandeiras.

A equipe verde adotou a nomeação de Tutti Green. Segundo os componentes, Tutti é de origem italiana e significa, literalmente, todos juntos, enquanto Green, do inglês, é traduzido como 'verde', dando a entender o significado da equipe como todos juntos verdes. Em sua bandeira, a equipe desenhou um jabuti, como símbolo. Do outro lado da experiência, a equipe amarela, focando na reciclagem, escolheu como nome Recicladores da Alegria, apresentando como justificativa, a importância da reciclagem para o meio ambiente, em conjunto com a alegria de realizar ações que prezam por tais práticas. Exemplificando isso, os componentes confeccionaram as letras da bandeira amarela com folhas de jornais.

Imagens 03 e 04: Bandeira da equipe verde e bandeira da equipe amarela
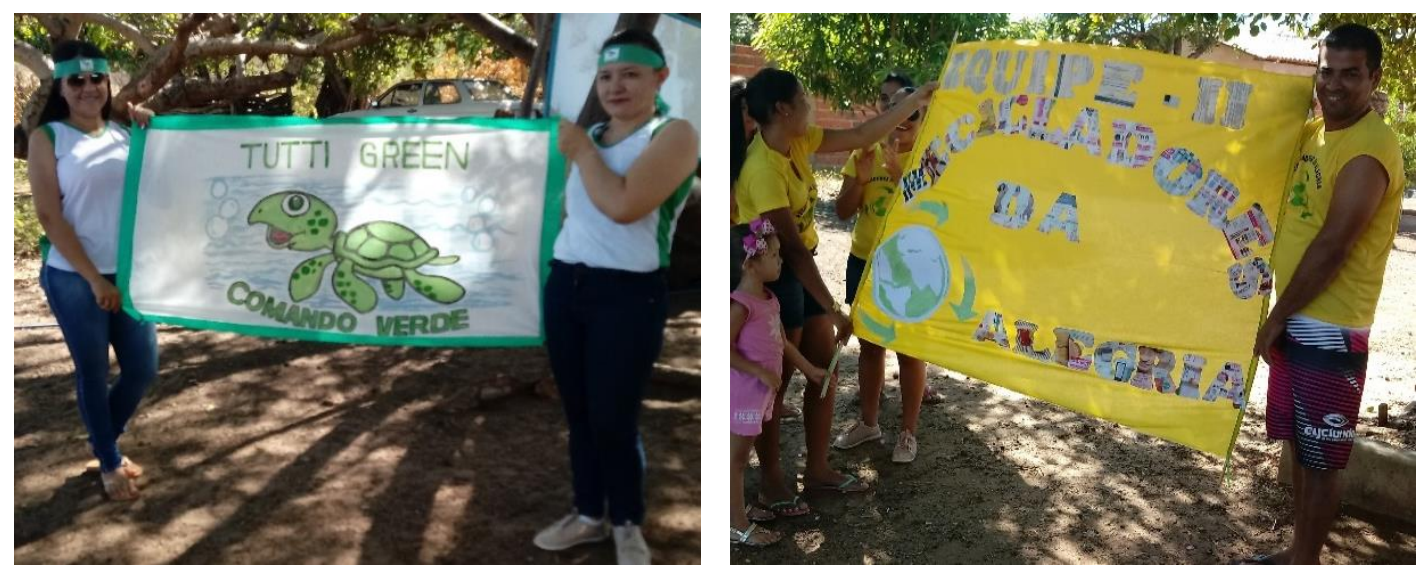

Fonte: Arquivo pessoal do professor/pesquisador (2018) 
As equipes tinham que expor seus mascotes. Com os alunos em conjunto, cada uma produziu o seu. A Tutti Green, chamou de Tutti um jabuti feito com folhas de jornais. A Recicladores da Alegria, mais uma vez na temática da reciclagem, denominou o mascote de 3 R's (Reduzir, Reutiliza e Reciclar), um peralta com tronco e cabeça formados por um caixa de papelão, braços e mãos de uma boneca, pernas de papéis de jornais e calçado em um tênis infantil.

Imagens 05 e 06: Mascote da Equipe Tutti Green e Mascote da Equipe Recicladores da Alegria
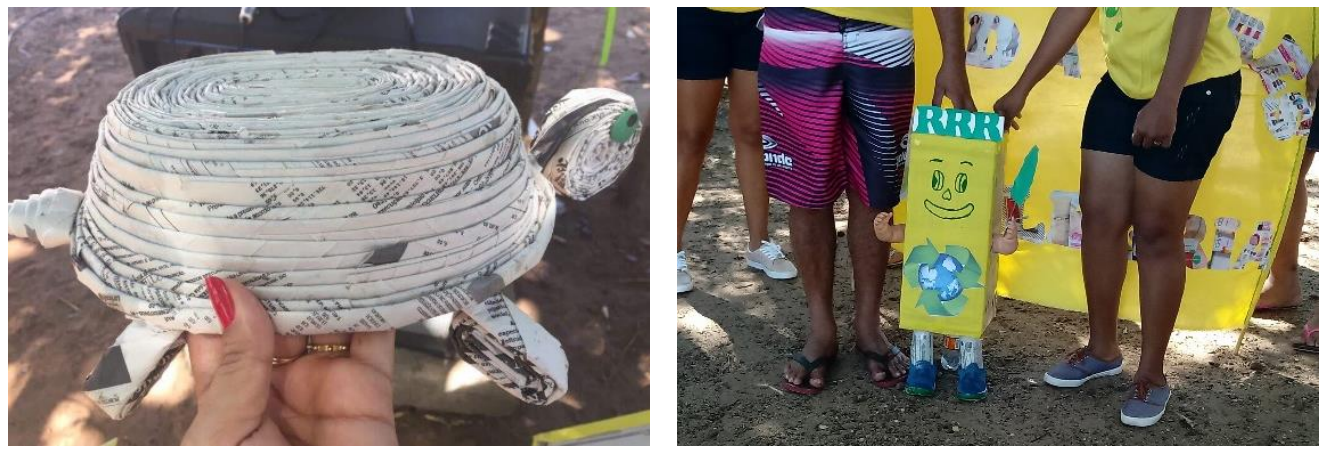

Fonte: Arquivo pessoal do professor/pesquisador (2018)

Os gritos de guerra de ambas foram animados e criativos, enaltecendo o desejo por vitória, força, garra, determinação e a união na busca pelos objetivos da gincana e a luta pela defesa do meio ambiente. Semelhantemente, as paródias musicais foram elaboradas enfatizando a consciência cidadã no relacionamento com os recursos naturais, por meio de um enfoque de responsabilidade participativa. A transformação das músicas originais dos gêneros do forró (Luiz Gonzaga) e sertanejo (Simone e Simara), ocorreu em um processo de interiorização da diversidade linguística musical em paralelo ao princípio legal instituído na Lei 9795/99, que considera o meio ambiente como um todo, nas suas interdependências entre o meio natural, o socioeconômico e o cultural, sob o enfoque da sustentabilidade (BRASIL, 1999).

Outra prova proposta antecipadamente aos alunos foi a confecção de roupas com material reciclado. Um casal de cada equipe desfilou com o traje totalmente reciclado, desde as sandálias até os acessórios femininos sobre a cabeça. 
Imagens 07 e 08: Casal de noivo (equipe verde) e casal despojado (equipe amarela)
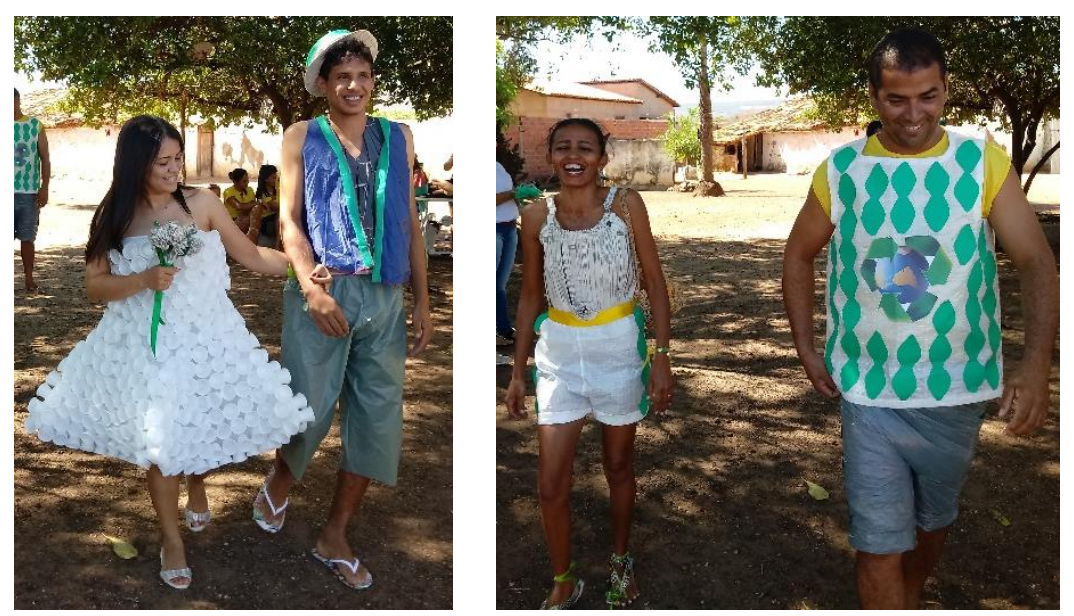

Fonte: Arquivo pessoal do professor/pesquisador (2018)

Dentre as confecções, a equipe verde apostou em um vestido de noiva, feito com copinhos descartáveis e buquê de flores artificiais reaproveitadas, enquanto o noivo vestia sua roupa de sacolas plásticas. Na outra equipe, o casal despojado se apresentou com um look tendo como matéria-prima principal, sacos de armazenar cereais, e ainda, a mulher usava brincos, colar, pulseira e bolsa de produtos reciclados.

Sobre os conhecimentos teóricos, os alunos estudaram o conteúdo da apostila acerca da Educação Ambiental e a Lei 9.795/99. Com base nisso, foram elaboradas duas tarefas: na primeira, os grupos teriam que montar o objetivo geral da EA corretamente, que estava impresso em papel e recortado; a segunda, foi a torta na cara, jogo de perguntas e respostas, em que os que erravam recebiam tortas no rosto. Tais atividades, conferem uma maneira dinâmica de estudar a teoria, contribuindo com a aprendizagem, a memorização e a compreensão dos aspectos literários e legais do assunto. Além do mais, fazer uso de inovações metodológicas não é abandonar por completo as atividades tradicionais, mas conciliá-las em prol de uma reflexividade a respeito das práticas pedagógicas (SAMPAIO; BARROS, 2015).

Dando continuidade às provas, as que seguem, não eram de conhecimento dos graduandos: $O$ jogo da forca, aplicado com nome de animais em extinção; a separação de figuras de materiais plásticos, de metal, de papel e de vidro nas devidas cores da coleta seletiva; o recolhimento do maior números de tampas de garrafas da piscina com uma colher presa a um cabo de vassoura, referindo-se à poluição das águas de rios, açudes e lagos da região; e, uma trilha ecológica com 
jogo de dado e andando por casas, com tarefas em equipe e individuais, que concentrou a reflexão sobre vários conteúdos da EA e meio ambiente.

$E$ ainda, artisticamente, mais duas provas, que prezaram pela criatividade $e$ expressões diversas. A confecção de um quadro, apenas com material natural encontrado dentro do ambiente da gincana e a outra, a produção de uma propaganda, conscientizando sobre os cuidados necessários com o meio ambiente. No improviso, as duas equipes encenaram peças teatrais.

$\mathrm{Na}$ atividade do quadro, as equipes utilizaram-se de sementes, frutas, folhas, artefatos encontrados no quintal, pedras, tijolos, telhas e outros recursos. A Tutti Green objetivou construir uma possível maquetes do sítio onde acontecia a gincana, intitulando-a como Nosso sítio. Os Recicladores da Alegria buscaram reviver o tempo de infância na zona rural, com o quadro Brincadeira de crianças, retratando quando brincavam de casinha improvisada.

Imagens 09 e 10: Quadro Nosso Sítio e Quadro Brincadeira de crianças
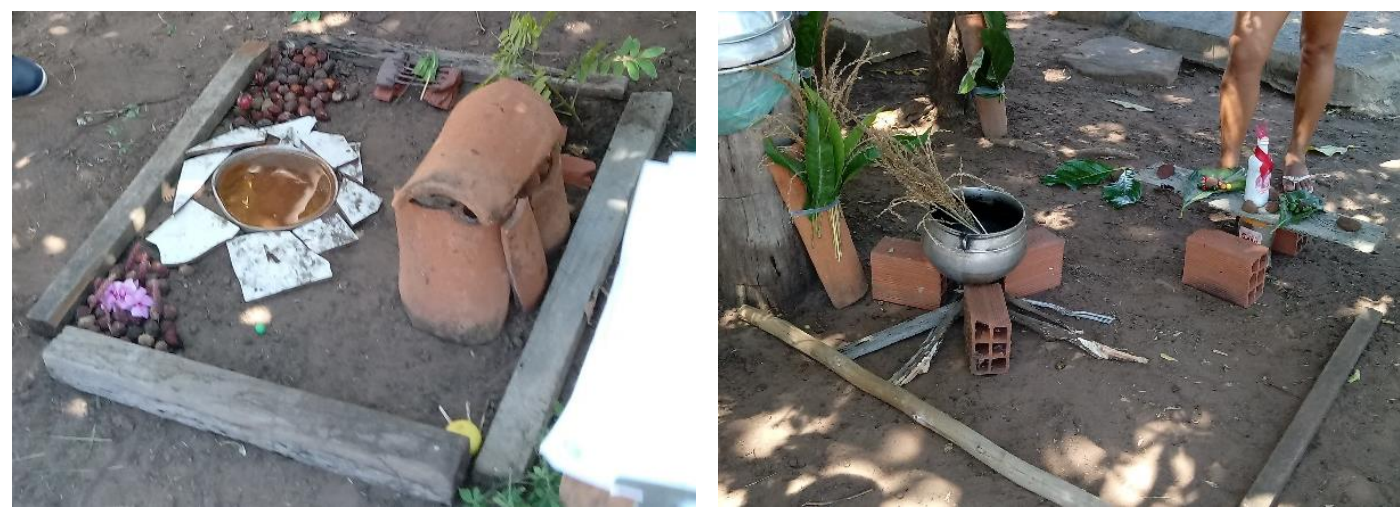

Fonte: Arquivo pessoal do professor/pesquisador (2018)

Como podemos notar, as formas de linguagens adotadas para a concretização das atividades proporcionaram aos alunos uma variedade expressiva em níveis e potências diferentes, espontâneas e desinibidas, diferentemente do que acontece na rotina de sala de aula. Em sistemas comunicativos e interativos criativos, os alunos compartilharam as ideias e informações na elaboração escrita, oral e artísticas, ou mesmo, no intercâmbio entre ambas, a exemplo, da paródia musical, pois sua utilização tem um cunho provocativo sobre o tema abordado delineado a partir da adequação e modificação de uma musicalidade estruturada já existente (BETTIO, 2010 apud NOGUEIRA; PAULA, 2017). 
Por outro lado, os discentes assimilaram símbolos linguísticos, como as cores da coleta seletiva de resíduos. De certo, em ambos os casos, os alunos se apropriaram dos recursos linguísticos para o desenvolvimento do raciocínio, da lógica e para memorização, tornando-os instrumentos constitutivos na formação dos pedagogos participantes.

Com o conjunto de provas propostas aos graduandos, uma vasta variedade de possibilidades experiências se abriu dentro da realização da gincana, legitimando-a, como mais do que uma diversificação metodológica ou pedagógica, mas uma oportunidade de produção de saberes nas (inter) faces de uma rede de (auto)formação de professores, conforme orienta Nóvoa (1997, p. 26), quando destaca que ela permite "[...] compreender a globalidade do sujeito, assumindo a formação como um processo interativo e dinâmico".

As tarefas desenvolvidas se expandiram dentro da aplicação do conhecimento teórico-prático da EA, abordando diversos ramos pertinentes à disciplina. Essa realidade evocou o caráter interdisciplinar alcançado com o desenvolvimento da gincana nesses moldes, por meio de uma única atividade, que foi capaz de englobar um universo mais vasto, amplo e abrangente de cada tema. Para Fernandez (2005), a interdisciplinaridade rompe barreiras e promove a abertura ao novo, assim, novos conhecimentos, novas estratégias e novos comportamentos foram gerados nos pedagogos em formação no decorrer das experiências.

Durante os acontecimentos da gincana, os discentes transcorreram processos progressivos em trilhas de aprendizagens em uma nova cultura de formação de professores, fazendo uso do termo de Nóvoa (1997), com o agenciamento de trocas e partilhas de experiências, sem as verdades do conhecimento fechado e acabado costumeiramente transmitido, sem possibilidade de refutação ou questionamento, mas por intermédio da construção simultânea de múltiplos sentidos para a vida e profissão docente. Larrosa (2002, p. 27) explica muito bem isso:

Este é o saber da experiência: o que se adquire no modo como alguém vai respondendo ao que vai lhe acontecendo ao longo da vida e no modo como vamos dando sentido ao acontecer do que nos acontece. No saber da experiência não se trata da verdade do que são as coisas, mas do sentido ou do sem-sentido do que nos acontece. E esse saber da experiência tem algumas características 
essenciais que o opõem, ponto por ponto, ao que entendemos como conhecimento.

Foi notável o trabalho conjunto nas equipes. O estímulo advindo através da delegação de tarefas do professor aos líderes e, posteriormente, dos líderes para as equipes, organizou as formas de interação e participação cooperativa entre os graduandos. Essa articulação é uma responsabilidade do professor, segundo Morán (2015). Sampaio; Barros (2015) também pontuam acerca do trabalho docente com gincanas, que no ambiente fora da sala de aula, as figuras de cooperação e amizade se intensificam, vinculando o aprendizado ao patamar importante do afeto.

Para Nóvoa (1997), a constituição humana e social dos profissionais da educação acontecem em um território habitado por atores individuais e coletivos. A gincana se instaurou como um lugar não estático e com habitantes em um desenvolvimento nômade, percorrendo pontos de passagens e de construção coletiva dos saberes, ou seja, além dos mais variados locais físicos em que a gincana foi vivida, considerando a IES, os seios familiares, as comunidades e a sociedade como um todo, os lugares subjetivos, virtuais e sociais também foram de assimilação contínua para a constituição docente.

A coletividade destacou-se como um ponto essencial no desenvolvimento das capacidades sensíveis humanas despertas pela interação nos jogos, nas dinâmicas e nas brincadeiras, em que a consciência individual deu lugar ao pensamento grupal, cada componente representou uma força maior conjugada a equipe. Observamos que a pluralização de pensamentos, ideias, posicionamentos, forças e estratégias foram se contrapondo e se ajustando e assim, formaram corpos coletivos vivos, que moveram-se em troca de olhares, afeiçoes, euforias, comemorações, acolhimentos, abraços, enfim, a interatividade humana capaz de gerar compadecimento e atos de intervenções pela vida, pela natureza e pelo meio ambiente.

$\mathrm{Na}$ concepção metodológica ativa, de Morán (2015), a articulação do trabalho em grupo é responsabilidade do professor, em procriar projetos em suas disciplinas, que envolvam essa dimensão coletiva no ativismo metodológico. E, portanto, jogos são uma sugestão do autor, aprendendo melhor com a prática, no compartilhamento dos interesses, pesquisas e vivências de uma educação 
horizontal, "[...] expressa em múltiplas interações grupais e personalizadas" (MORÁN, 2015, p. 26).

Reforçando a coletividade interacional, Nóvoa (1997) afirma que as dimensões coletivas em práticas de formação funcionam como incentivadoras da emancipação profissional e autonomia produtora de saberes e valores. No diálogo com os alunos que participaram da gincana, foi possível sentir a entonação de valores humanistas, holísticos, democráticos, participativos, culturais e em abordagem ambientalista. Foram esses discursos que confirmam o alcance dos objetivos da experiência, proposta e vivenciada com os graduandos.

Além de todas discussões apresentadas, destacamos os processos de criatividade trazidos à tona pelos graduandos, nos mínimos detalhes e em todas as provas propostas. Conforme Sampaio; Barros (2015), em gincanas, isso é esperado e importante para o desenvolvimento acadêmico e social.

Por fim, a gincana encerrou com um círculo composto por alunos e professor, não valorizando a competitividade em se ter uma equipe que obteve mais pontos, mas revitalizando 0 aspecto cooperativo e 0 desenvolvimento socioambiental e de relações interpessoais proporcionados aos acadêmicos.

Imagens 11 e 12: Encerramento da gincana e professor com as equipes
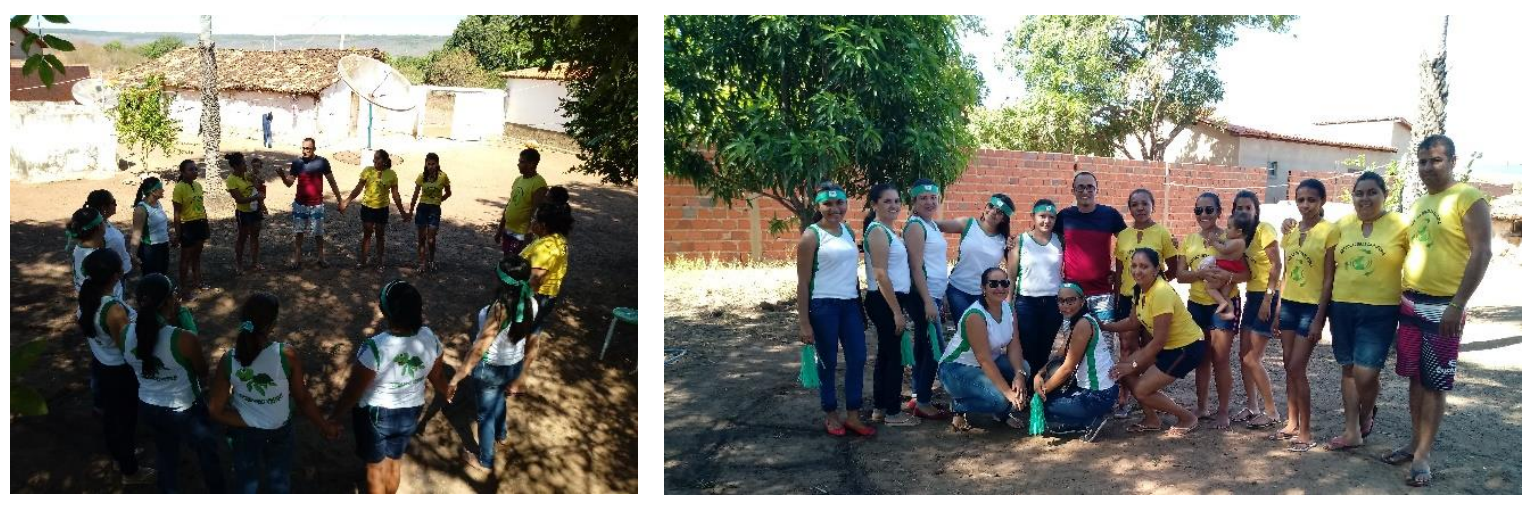

Fonte: Arquivo pessoal do professor/pesquisador (2018)

O último momento, ainda em círculo, foi de autoavaliação por parte de todos os sujeitos envolvidos na prática educativa, pois a avaliação do processo educativo deve ser permanente (BRASIL, 1999) e capaz de dimensionar a produção dos saberes experienciais. 


\section{CONSIDERAÇÕES FINAIS}

Na premissa de que a experiência que nos passa, nos afeta de algum modo e em nós produz algo, deixa marcas e vestígios, ocasiona feitos e efeitos, elucida-se que a experiência docente relatada foi marcante no processo constitutivo da formação dos sujeitos professores da educação básica. Na pessoa do professor, fica evidente os registros da iniciativa de um trabalho significativo, que valoriza os alunos, suas culturas e problemáticas locais nos percursos formativos.

Sobre a gincana, o conjunto de tarefas realizadas foi capaz de gerar múltiplos sentidos para a formação acadêmica, profissional, social, cultural e cidadã dos graduandos em Pedagogia, bem como, um forte componente metodológico no desenvolvimento da disciplina de Gestão e Educação Ambiental pelo professor de nível superior. Uma forma ativa, participativa, lúdica e responsável de desenvolver em teoria e praticidade a EA, tão emergente de debates e ações contínuos no espaço acadêmico, assim como outras temáticas.

Assim, foi trilhado um caminho divertido e rico em interações, experiências e expressões humanas e formativas, que propiciaram o alcance do objetivo proposto com a gincana, firmando-a como um recurso metodológico de grande valia no processo de formação de professores, sendo um espaço adaptável à todas as áreas, públicos e níveis de ensino formalizado.

Portanto, a experiência relatada evidencia que, conforme o lema da gincana, é, tornando-se "um só", um só povo, em um só propósito, que podemos lutar por um Brasil melhor, em todos os âmbitos e esferas, mais especificamente, na preservação do meio ambiente. É com professores-experimentadores-apaixonados e em uma linguagem interativa, que as IES progredirão como espaços inovadores, participativos e experienciais constitutivo de professores.

\section{REFERÊNCIAS}

BRASIL. Lei 9.795, de 27 de abril de 1999. Dispõe sobre a educação ambiental, institui a Política Nacional de Educação Ambiental e dá outras providências. Presidência da República. Brasília, 27 de abril de 1999. Disponível em: < http://www2.mma.gov.br/port/conama/legiabre.cfm?codlegi=321 >. Acesso em: 03 set. 2018. 
DICIO. Dicionário Online de Português. [S.I.]: Significado de gincana. Disponível em: < https://www.dicio.com.br/gincana/ >. Acesso em: 03 out. 2018.

FERNANDEZ, Verônica Cazarotto. Educação Ambiental: um desafio a Pedagogia. 2005. 81 f. Monografia (Especialização em Educação Ambiental) - Universidade Federal de Santa Maria, Santa Maria, 2005. Disponível em: < https://repositorio.ufsm.br/bitstream/handle/1/573/Fernandez Veronica Cazarotto.pd $\underline{\text { f? sequence }=1}>$. Acesso em: 03 set. 2018.

LARROSA, Jorge. Notas sobre a experiência e o saber de experiência. Revista Brasileira de Educação, Campinas, v. 1, n.19, p. 20-28, abr. 2002. Disponível em: < http://www.scielo.br/pdf/rbedu/n19/n19a02.pdf >. Acesso em: 01 out. 2018.

LEFF, E. Saber ambiental: sustentabilidade, racionalidade, complexidade e poder. 2. ed. Rio de Janeiro: Vozes, 2002.

MINAYO, Maria Cecília de Souza. Pesquisa social: teoria, método e criatividade. 18. ed. Petrópolis: Vozes, 2001.

MORÁN, José. Mudando a educação com metodologias ativas. In: SOUZA, C. A. de; MORALES, O. E. T. (Org.). Convergências midiáticas, educação e cidadania: aproximações jovens. Ponta Grossa: UEPG; PROEX, 2015. (Coleção Mídias Contemporâneas). v. 2. p. 15-33. Disponível em: < http://www2.eca.usp.br/moran.wpcontent/uploads/2013/12/mudandomoran.pdf $>$. Acesso em: 05 out. 2018.

MORIN, Edgar. Educação e complexidade: os setes saberes e outros ensaios. Tradução de Edgard de Assis Carvalho. 4. ed. São Paulo: Cortez, 2007.

NOGUEIRA, Jorge Luís; PAULA, Neidimar Lopes Matias de. O uso da paródia como estratégia de aprendizagem no ensino de química: um relato de experiência. In: Congresso Nacional de Educação, 4, João Pessoa, nov. 2017. Anais eletrônicos... João Pessoa: Editora Realize, 2017. Disponível em: < https://editorarealize.com.br/revistas/conedu/trabalhos/TRABALHO EV073 MD4 S A16 ID7821 12102017201621.pdf >. Acesso em: 07 out. 2018.

NÓVOA, António. Formação de professores e profissão docente. In: (Coord.). Os professores e a sua formação. Lisboa: Dom Quixote, 1997.

PEQUENO, Maria Gorete; GUIMARÃES, Jean Philippe; ALMEIDA, Maria da Conceição V. Educação ambiental no ensino superior: qual seu lugar nos processos de formação docente? In: Congresso Internacional da Afirse e V Colóquio Nacional, Anais eletrônicos... João Pessoa, 2009, p. 01-13. Disponível em: < http://afirse.com/archives/cd11/GT\%2007\%20\%20POL\%C3\%8DTICAS\%20E\%20PR\%C3\%81TICAS\%20CURRICULARES/719 E DUCA\%C3\%87\%C3\%830\%20AMBIENTAL\%20NO\%20ENSINO\%20SUPERIOR.pd f >. Acesso em: 03 set. 2018.

SAMPAIO, Jemerson Souza; BARROS, José da Silva. O uso de gincanas pedagógicas para auxiliar o ensino aprendizagem. In: Congresso Nacional de 
Educação, 2, Campina Grande, out. 2015. Anais eletrônicos... Campina Grande: Editora Realize, 2015. Disponível em: <

http://www.editorarealize.com.br/revistas/conedu/trabalhos/TRABALHO EV045 MD 1 SA8 ID294 12082015120658.pdf >. Acesso em: 03 set. 2018. 